\title{
To work or not to work: that is the question
}

\author{
R C B Aitken, P Cornes
}

\begin{abstract}
Medical publications contain numerous references to obstacles or disincentives confronting patients who wish to return to work after illness or injury. Current developments of importance to this aspect of medical practice and four recent studies, conducted in Edinburgh, that may contribute to the continuing debate about how best to deal with such problems are reviewed. The studies concern measurement of rehabilitation status, identification of potential to benefit from rehabilitation, medical contributions to occupational assessment of accident victims, and patients' patterns of involvement with medical and vocational rehabilitation services. It is concluded that coordination between services is still a major problem and is likely to remain so if more effective bridging between medical and vocational aspects of rehabilitation is not achieved.
\end{abstract}

If medical opinion on the employment of people with disabilities were sampled there is little doubt that the balance of such opinion would be of a negative, pessimistic persuasion. Most observations would inevitably refer to some, it not all, of the following features:

Patients' low levels of motivation

The disincentive effects on return to work of current levels of benefit or compensation, or both

The comparative ineffectiveness of public employment and training services for the disabled The difficulty, if not impossibility, of finding or creating new jobs in a labour market characterised by high unemployment

The unsuitability of most severely disabled people for the jobs that are available

The lack of suitable opportunities in sheltered employment for those who are unable to work under normal, competitive conditions.

Two points may be noted about these frequently made observations. The first is that they include no

Rehabilitation Studies Unit, University of Edinburgh, Princess Margaret Rose Orthopaedic Hospital, Edinburgh EH10 7ED

R C B Aitken, P Cornes reference to the role of doctors-the decisions made or the advice given on return to work in hospitals, in general practice, or by occupational health special- $\vec{\omega}$ ists. The second is that if these are the prevailingo views it would be most surprising if their generallyo pessimistic tone were not in some measure conveyed to patients-lowering their expectations and, in turn reinforcing an already generally negative picture of the social and economic consequences of dis- $-\vec{\omega}$ ablement. Small wonder therefore that "To work oro not to work" is such an important issue for so many? patients on recovery from serious injury or illness.

\section{Developments}

But need the picture be so black or are there grounds for more optimistic evaluation, albeit qualified? There are three encouraging developments. The first is the publication in 1988 of Fitness For Work: The Medical Aspects. ${ }^{1}$ This authoritative work, presenting a refined but readily digestable and up to date review of occupational health is a much needed beacon that will guide future progress not only in this specialty but for many allied professions. The Faculty of Occupational Medicine is to be con-7 gratulated for its foresight in commissioning this much needed book, as are the editors for its generalo excellence.

The second development concerns applications of new technology to help the employment of severelyo disabled people. Some intractable and as yet unsolved problems remain in this sphere, not least 5 where the rapidly increasing number of survivors of 5 severe head injury are concerned. Nevertheless, it is but a short while ago that the primary concern for patients with spinal cord injury was with life expect- $N$ ancy. It is encouraging for all concerned to note the conclusions of a recent study regarding a shift from this focal concern on the part of patients with such $\omega$ injuries to that of expectation of life or the quality of

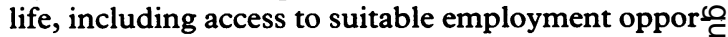
tunities. ${ }^{2}$ This was the ideal outcome envisaged by Guttmann and his co-workers at Stoke Mandeville and elsewhere 40 years ago. Access to new tech- -0 nology, the heightened expectations of disablect people themselves, and the availability of appropriate? employment programmes such as the Department of Employment's remote working scheme, are now combining to convert that dream into reality for an increasing number of patients each year. The num? 
ber benefiting in this way remains small. Those who have found such employment, however, are an important group whose achievements are an important indication of the art of the possible.

The third source of encouragement to be found in recent developments is one of particular importance and concerns the conduct of appropriate research and development work. It should not be overlooked that it is only 22 years since Townsend delivered his celebrated lecture on "The Disabled in Society" to the Royal College of Surgeons. ${ }^{3}$ In this he drew attention to the lack of fundamental knowledge about the true extent of disablement in our society and the consequent tendency, in the absence of such knowledge, for provision to be made somewhat capriciously for some groups but not others. Townsend's salutory warning was a stimulus for the DHSS (Amelia Harris) survey of disablement undertaken in the early $1970 \mathrm{~s}^{4}$ and also for the Chronically Sick and Disabled Persons Act, 1970, which among other things, although unsuccessfully, required local authorities to survey needs within their own domains. It also stimulated wider reviews-most notably by the Standing Medical Advisory Committee whose subcommittees chaired by Tunbridge and Mair examined provision of rehabilitation services in England and Wales and in Scotland respectively. ${ }^{56}$

All these initial responses to Townsend's warning underlined the extent of earlier neglect of this subject and just how bare our store of knowledge was. It was in this climate that the chair of rehabilitation studies at Edinburgh and the Europe chair in rehabilitation at Southampton were created. Whereas it cannot be claimed that support for rehabilitation research, particularly vocational aspects, has been overgenerous during the 15 years since these appointments, some substantial progress has been made. This has been $(a)$ enhancing knowledge about the nature and scale of some of the problems confronting disabled people who wish to enter or return to work after illness or injury and (b) about the effectiveness of policy and practice from the perspectives of both national programmes and employers' occupational health and personal management procedures. More recently, this knowledge has been used to underpin the efforts that government, employers, unions, and other organisations have made to promote "good practice" on the employment of disabled people, to develop new vocational rehabilitation services, and to increase the number of people with disabilities in gainful employment.

For all that has been accomplished to date, there is much more that could and should be done in both "pure" and "applied" senses. There has been no more timely a reminder of this than the recent OPCS survey report finding that only $31 \%$ of disabled people under pensionable age in Great Britain are employed. ${ }^{7}$ Those who have been nurtured on a diet of Department of Employment statistics would undoubtedly be surprised by this low figure, several times worse than the most pessimistic published official estimate of the problem. A survey conducted in Edinburgh, of an admittedly more tightly defined sample than the one by the OPCS, found an unemployment rate of $88 \%$. Fifteen per cent of the $88 \%$ considered themselves available for employment, with the remainder "out of the labour market" for a variety of reasons mainly associated with disablement or continuing ill health. If such data indicate the scale of the mountain to be climbed it is apparent that we are still negotiating the foothills. Again, to date, the common standards for work assessment, identified as essential for further progress a decade ago by the National Advisory Council on the Employment of Disabled People, have yet to be developed and implemented, despite some limited progress after the introduction of the VALPAR Corporation's system of occupational assessment into employment rehabilitation centres in recent years. Certainly employers' requirements, as recognised in Fitness for Work: The Medical Aspects, have yet to be met. There is therefore an urgent need for further work on this topic, ideally founded on a multiprofessional, scientific basis.

Nevertheless, as indicated earlier, some progress is being made. This review looks at four aspects of rehabilitation research that should help the debate about resourcing for the future and the most desirable basis for future research, policy, and practice. The four examples are: the measurement of rehabilitation status, identification of potential to benefit from rehabilitation services, an analysis of medical (predominantly orthopaedic surgeons') contributions to occupational assessment of the victims of road traffic accidents and accidents at work, and studies of patients' involvement with rehabilitation and resettlement services which suggest a need for better coordination in delivering the services required in individual cases.

Measurement of rehabilitation status: the Edinburgh rehabilitation status scale

The publication in 1980 of the World Health Organisation's International Classification of Impairments, Disabilities, and Handicaps has been of great help in discriminating between those consequences of injury or impairment that result in reduced or lost function (disabilities) and those that are of social or situational origin (handicap) and prevent the impaired individuals from performing social roles normal for someone of the same age, sex, social class, etc. ${ }^{9}$ This classification clearly establishes that disability and handicap are not interchangeable terms. The same disability (loss of a finger) can have quite different consequences for a manual labourer, who would not be handicapped by it, and a concert pianist who 
undoubtedly would be. A recent experiment by the Spastics Society has shown just how handicapping even the declaration of a disability on a job application form can be ${ }^{10}$ Paired job applications that were similar in every respect, except for the declaration of a disability in one but not in the other, were submitted in response to a series of publicly advertised vacancies. Those that declared a disability were considerably less successful in securing invitations to interview than the applications that did not refer to disability, highlighting the handicapping effect of personnel selection procedures across a wide range of employment settings.

While it is necessary to look at both disability and handicap, measurement of the consequences of injury or impairment has tended to concentrate more on the former than the latter. As a result there are many more functional measures of activities of daily living-for instance, the Barthel index-than more global assessments that also take social roles into consideration. The Edinburgh rehabilitation status scale (ERSS) is an example of the latter type. ${ }^{11}$ Based on earlier work with psychiatric patients, which showed that current status and medicosocial change could be measured satisfactorily in individuals and groups by means of a four dimensional scale adapted from the handicap section of the WHO classification, this scale provides a similar measurement of medicosocial performance in which change is likely to occur during rehabilitation of a wide range of patients. There are four subscales:

Independence/dependence (SUPP) describing the frequency of the patient's acceptance of support and the extent to which he or she relies on others for self care, economic arrangements, and the administration of any medicine or treatment required.

Activity/inactivity (INACT) measures the ability to initiate and perform the physical and intellectual processes necessary in occupations, home life, and leisure. (There is no emphasis on paid employment.) Social integrations/isolation (ISOL) assesses social behaviour from the perspective of involvement with others, rating the extent and quality of domestic and social participation.

Effect of symptoms on lifestyle (EFF:SYM) grades the frequency and severity of any symptoms or signs and the difficulties and distress that arise.

Each subscale is graded from 0 to 7 based on review of information normally available in rehabilitation practice. Scores therefore provide a rating on each dimension as well as a global rating of each individual assessed and an indication of any anomalies between subscales. Practical experience with ERSS has shown that it can be completed in as little as five minutes if the patient is known to the rater, and also that clinicians are particularly comfortable with its application because it is based on categories and concepts with which they are familiar. It can also be completed easily by a multiprofessional team. Evaluation of the scale has yielded good evidence of
its validity and reliability and also of its sensitivity as a measure of change over time. Comparison with parallel assessments of patients on the Barthel index and PULSES profile suggests that the latter two assessments emphasise social factors to a lesser degree.

Because the ERSS is not tied to any special theoretical assumptions its data may serve as outcome dependent variables in any type of trial, with or without more detailed descriptive instruments, to measure physical, psychological, social, and administrative indices. The mean total scores and dimensional profile of identified groups are also relevant to $\vec{t}$ studies of quality of life and are being used in $V$ community studies of disabled people. Expressed as $\vec{\omega}$ high, moderate, or low levels of functioning, they might also be used in relation to staff workloads and $\frac{}{工}$ other costs incurred in the management of partially rehabilitated patients. The scale has yet to be applied in an occupational health context, but is also expected to have a similar potential for practical application in such settings.

\section{Identifying potential to benefit from rehabilitation: the VRI}

If work on the ERSS has developed to a stage at which applications to occupational settings are beginning to be considered, other work on measurement is firmly rooted in that context. One example is the vocational rehabilitation index (VRI) developed in Edinburgh as part of a series of studies financed by the Association of British Insurers since 1980 (P Cornes, unpublished data). One aspect of the programme has concentrated on the rehabilitation and return to work of people of working age who were injured at work or in road traffic accidents and who subsequently pursued claims for compensation for their injuries and other related losses. ${ }^{12}$ This series of studies has generated several practical outcomes. $\frac{D}{2}$ One is the possibility of differentiating at a relatively early stage of claims negotiations between claimants $N$ who will return to work and those who will not. This opens up the further possibility of early identification of claimants who are unlikely to return to work without specialist help, with a view to referring them to appropriate services.

The background to this development was provided by reviews of insurance files on a national sample of ? 818 claimants who were of working age and in ${ }^{\circ}$ employment when injured at work or in road traffic accidents. Their claims were settled by one company $\stackrel{\odot}{\square}$ over a period of two years for amounts of between $\unrhd$ $£ 5000$ and $£ 305000$. (Ninety per cent of all personal $\frac{}{2}$ injury claims today are concluded by settlements of $\varnothing$ less than $£ 5000$.) There were 97 fatal injuries. Of the 
remainder, $13 \%$ had minor injuries that had not responded to conventional treatment and $6 \%$ suffered serious or catastrophic injuries. Most injuries $(81 \%)$, however, were classified as moderately severe or severe.

Analysis of information about the survivors yielded four significant findings.

There was an interval of two years on average between time taken to complete medical treatment and time taken to settle claims.

During this period, $66 \%$ of claimants returned to work, $4 \%$ left the labour market, and 3\% remained too ill or disabled to work. The remaining $27 \%$, while fit to return to work, did not do so-including $7 \%$ of all claimants who were suspected of functional overlay, secondary gain, malingering, or poor motivation.

Whereas the latter $27 \%$-and, indeed, some late returners-might have been referred to appropriate (vocational) rehabilitation services, fewer than one in 20 claimants had any reported involvement with possible sources of help, including occupational therapy and various Department of Employment services. (Those referrals that were made tended to be as a last resort, late on, when all other measures had failed.)

Employment outcome (in work or not in work) at settlement could be predicted with around $95 \%$ accuracy.

That outcome at settlement was predictablelinked to other evidence that $80 \%$ of all claimants who returned to work did so within a year of injurystimulated interest in a new problem. Was it possible to identify, among claimants who did not return to work within a year of injury, those who might be helped to do so by referral to appropriate services? If so could this be done using information that is routinely available to insurers, or which they could obtain, during that period?

Further statistical analysis showed seven items of information that distinguished between claimants who returned to work within a year of injury and those who did so later or not at all. Simply scaledthat is, ordinally - in accordance with the percentage of claimants in each scoring category who returned to work, these seven variables were combined into the VRI. A person's score is the sum of his or her ratings on all seven items and will fall somewhere between a minimum of 7 and a maximum of 24 .

Various steps have been taken to establish the reliability and validity of this index, as well as the extent to which it may be used with other disabled people. Face validity, however, is clearly shown by the table showing the percentage of claimants in four score bands who were in employment $(a)$ one year after injury and $(b)$ at settlement (on average three years after injury). These data underline the extent to which higher ratings on the VRI-based on seven
Vocational rehabilitation index

\begin{tabular}{lll}
\hline & \multicolumn{2}{l}{ Percentage in employment } \\
\cline { 2 - 3 } VRI score & Within 12 months & By settlement \\
\hline $7-11$ & 86 & 97 \\
$12-14$ & 45 & 68 \\
$15-17$ & 10 & 24 \\
$18-24$ & 5 & 5 \\
\hline
\end{tabular}

items of information available within a year of injury - are indicative of decreasing likelihood of return to work and hence increasing need for help with vocational rehabilitation.

The potential of the VRI as an aid to rehabilitation decision making is illustrated by the cases that make up each of the four main bands. Detailed examination of individual case histories and further statistical comparisons between claimants whose scores fall into each band suggested a further potential application. It could be used as a guide to the type of help needed by, and the most appropriate vocational objectives for, individuals whose scores fall into each band or range.

As with the ERSS, work on the VRI scale is still proceeding, including its application prospectively in a new project concerned with the implementation of a rehabilitation coordinator service for personal injury claimants. ${ }^{13}$ At the moment one may conclude that sufficient progress has been made on development of the VRI to suggest that it has considerable potential for wider application not only in insurance where it is already being used in rehabilitation and underwriting activities, but also in other contexts.

\section{Professional input to rehabilitation decision making: medical reports}

One consequence of taking the concept of handicap seriously should be the recognition that advice given or decisions taken by those engaged in the rehabilitative process can both facilitate and impede patients' progress. The earlier example of the Spastics Society project highlighting how personnel screening procedures select out disabled job applicants is a telling illustration of the professional or societal roots of handicap. ${ }^{10}$ Studies of insurance claimants have examined in detail the content of medical reports prepared for medicolegal purposes and have evaluated the extent to which current practice meets the whole range of recipients' requirements for information and advice ${ }^{14}$ (and P Cornes).

Materials for this investigation comprised 602 medical reports prepared by 400 consultants (most of whom were orthopaedic surgeons) on a representative sample of 203 employer's liability and third party motor claimants. Analysis of this material (a) 
assessed consultants' frequency of compliance with published guidance outlining 28 "essentials" of medical reporting and $(b)$ was supported by detailed content analysis of consultants' observations on such occupationally relevant topics as residual disablement, employment handicap, and referral to vocational rehabilitation services. ${ }^{15}$

Results indicated that a common core of clinical themes (incident, injuries, treatment and response to treatment, examination, and prognosis), comprising two thirds of the contents of reports, was most often covered and most comprehensively dealt with, generally to a high standard. But these clinical themes embrace only part of the wider clinical and non-clinical framework of information required by recipients. Other aspects, including residual disability, occupational data, employment handicap, and rehabilitation, were touched on much less often and dealt with much less adequately. For example, $25^{\circ}$ o of the consultants did not even provide the patient's job title and more detailed occupational information was missing from $50 \%$ of all cases. Coverage of residual disability was based on rough rules of thumb rather than objective assessment in all but a few cases (in which injuries had resulted in hearing loss or visual disabilities). It was difficult, if not impossible, therefore, to relate descriptions of disablement to normative standards of performance. Advice with regard to employment handicap largely consisted in unhelpful pointers to requirements for light work and restrictions were stated in the most general, prohibitive terms-for example, "no lifting" or "no standing" as compared with advice based on formal assessment to avoid jobs that would entail lifting more than a specified weight or that necessitated standing for longer than a specified period. All who support the strongly argued case in Fitness for Work: The Medical Aspects to match work to patients' residual abilities will be disappointed that scrutiny of this advice failed to unearth a single example in which consideration had been given to the patients' requirements for technical aids to employment, job redesign, or other workplace accommodations. Referral to vocational rehabilitation for more detailed occupational assessment was recommended in less than $3 \%$ of all cases.

In the light of these findings, there must be some doubt about the capability of traditional clinical case management procedures, in cases of such severe or more serious injury, to provide effective advice on return to work. If more patients are to exercise their option to work rather than (by default) not to work, there is a need for much more attention to the vocational aspects of rehabilitation. Experience with personal injury claimants would suggest that in cases of moderate injury the minimum standard to be aimed for should include formal assessment of residual function and consideration of any social or occupational disadvantage. In severely or more 울 seriously injured cases there is a clear need for $\overrightarrow{\vec{F}}$ multiprofessional involvement over time. At the $\stackrel{9}{?}$ present time, there are few resources capable of $\bar{C}$ meeting the latter types of need for assessment and 흠 rehabilitation services. More comprehensive provi- $\frac{D}{\triangle}$ sion might be made through designated regional $\propto$ centres or private agencies specialising in these tasks.

\section{Requirement for better coordination in delivery of needed services}

Although a case may be made for some new services, it should not be overlooked that our country is $\mathbb{\Phi}$ already comparatively well provided with services to help rehabilitation and return to work. For some. $\overrightarrow{\mathrm{v}}$ patients, the main difficulty is gaining access to such services at the time when they can obtain maximum $\vec{\omega}$ benefit from referral. This problem was highlighted by Blaxter in the mid 1970s in a study that showed $\frac{}{5}$ just how complex the network of services can be in a city of medium size population. ${ }^{16}$ Given that complexity, which many of the professionals concerned do not fully comprehend, it is perhaps not too surprising that patients are unable to find their way through this maze unaided.

This problem was reviewed in great depth by a working party of the National Advisory Council on the Employment of Disabled People in 1979-80. ${ }^{17}$ That working party produced a blueprint for a new professional role HELP (health and employment liaison person) to provide the missing "fixing" or case coordinating function that would enable patients to make a smoother transition between needed medical, social, and occupational services, and recommended urgent attention to the setting up and evaluation of a HELP scheme. This recommendation was accepted but never implemented-apparently because the (then) Department of Health and Social Security and Manpower Services Commission could not agree over the financing of the scheme.

While government has allowed the grass to grow under its feet, the need for such coordination has not $\rightarrow$ diminished. The absence of onward referral from medical rehabilitation to occupational therapy and $N$ other relevant vocational rehabilitation services is not confined to the personal injury claimants cited in the earlier example. It is much more general. A recent review of patients treated for leg fractures in an Edinburgh hospital-fewer than $10 \%$ of whom were $c$ engaged in or contemplating litigation-found exactly the same low levels of onward referral to other ? services that could assist with social and vocational aspects of rehabilitation ( $\mathrm{H} \mathrm{J}$ Watson, unpublished data).

The evidence from these reviews and studies has $\stackrel{\mathbb{Q}}{\circ}$ convinced the researchers at Edinburgh not just of $\overline{0}$ the need for better coordination but to embark on some practical initiatives to achieve better inter- 
professional links and improved liaison between all the agencies engaged in planning services. While, in liaison with the local health board, they are hoping soon to see the appointment of disability networks with designated key workers undertaking this role in local health districts, ${ }^{18}$ the insurance based studies have already generated two practical examples. In one case the market leader in the permanent health insurance field was helped to launch and expand a disability counselling service for its claimants using nurses trained in Edinburgh in appropriate assessment, rehabilitation, and case co-ordination skills. ${ }^{19}$ In the other they are collaborating with four insurance companies to provide a similar service for personal injury claimants. In the latter case the "coordinator" is a member of the rehabilitation studies unit's staff and the service she is providing is being formally evaluated in the context of a controlled trial. $^{13}$

\section{Conclusions}

This review has concentrated mainly on examples of research undertaken at Edinburgh because we are most knowledgeable about our own scene. There is no intention, however, of claiming any monopoly for Edinburgh. A brief glimpse through relevant journals and the programmes of scientific meetings of the Society for Research in Rehabilitation would quickly refute such a claim. Researchers in Edinburgh and elsewhere, however, must continue with work based on good science with clear practical applications in order to provide high quality, soundly based advice for policy decision makers and administrators who are responsible for providing the services.

In the past in this country there has been a clear division between medical and vocational aspects of rehabilitation-a division which may be traced back over 50 years to the government of the day's disinclination to accept the recommendation of the Delevigne Committee for more integrated provision. ${ }^{20}$ While this remained Beveridge's vision (his proposal, after all, was for a comprehensive National Health and Rehabilitation Service), ${ }^{21}$ subsequent developments have not helped its realisation. Instead, there has been a fragmented, uncoordinated development of services that has not met patients' needs and has given rise to an urgent requirement for better coordination.

There must be a serious doubt about our ability to enhance coordination while services remain under different authorities-one committed to a dedicated amateur approach with little interest in or concern for development of practice based on the application of science and the other professional in its orientation and committed to a scientific approach. In comparison with other industrial nations, the United Kingdom's investment in vocational rehabilitation has been meagre and piecemeal. Its future might be better assured if it were more adequately resourced within the broader framework of rehabilitation medicine. In that context more could be done to encourage a more professional, scientifically based development and to enable vocational objectives to be better integrated with other rehabilitative aims and functions. People disabled by illness or injury might then have more realistic and more positive options to choose between when confronted by the question "To work or not to work?"

This article is based on a lecture given to the Faculty of Occupational Medicine, London, on 10 May 1989. Support from the Association of British Insurers for the preparation of this article and some of the research and development work it describes is gratefully acknowledged.

1 Edwards FC, McCallum RI, Taylor PJ, eds. Fitness for work: the medical aspects. Oxford: Oxford University Press, 1988.

2 Oliver M, Zarb G, Silver J, Moore M, Salisbury V. Walking into darkness: the experience of spinal cord injury. Basingstoke: MacMillan, 1988.

3 Townsend P. The disabled in society. London: Greater London Association for the Disabled, 1967.

4 Harris A, Cox E, Smith CRW. Handicapped and impaired in Great Britain. Part 1. London: HMSO, 1971.

5 Standing Medical Advisory Committee. Rehabilitation. London: HMSO, 1972. (Tunbridge Committee.)

6 Standing Medical Advisory Committee. Medical rehabilitation: the pattern for the future. Edinburgh: HMSO, 1972. (Mair Committee.)

7 Martin J, White A, Meltzer H. Disabled adults: services, transport and employment. (OPCS surveys of disability in Great Britain report 4.) London: HMSO, 1989.

8 McAndrew L, Hanley J. Survey of the younger disabled in the community in Lothian. Edinburgh: Rehabilitation Studies Unit, 1988.

9 World Health Organisation. International classification of impairments, disabilities, and handicaps. Geneva: WHO, 1980.

10 Fry E. An equal chance for disabled people? A study of discrimination in employment. London: Spastics Society, 1986.

11 Affleck JW, Aitken RCB, Hunter JAA, McGuire RJ, Roy CW Rehabilitation status: a measure of medicosocial dysfunction Lancet 1988; i:230-3.

12 Cornes P, Bochel HM, Aitken RCB. Rehabilitation and return to work of employers' liability claimants. International Journal of Rehabilitation Research 1986;9:119-28.

13 Davey C, Cornes P. A rehabilitation co-ordinator service for personal injury claimants. International Journal of Rehabilitation Research 1989;12:96-8.

14 Cornes P, Bochel HM. Do medicolegal reports meet insurers' requirements? Post Magazine and Insurance Monitor 1985;146:2035-7.

15 Cornes P, Bochel HM. Fitness for work: medicolegal assessments of residual disability and employment handicap. International Journal of Rehabilitation Research 1987;10(suppl 5):309-17.

16 Blaxter M. The meaning of disability. London: Heinemann, 1976.

17 National Advisory Council on the Employment of Disabled People. Current arrangements for liaison between health, social and employment services for the rehabilitation and resettlement of disabled people. London: Department of Employment, 1980.

18 Hunter J, Walker J. The role of a rehabilitation medicine service. Edinburgh: Rehabilitation Studies Unit, 1989.

19 Cornes P. At last a rehabilitation counselling service. Post Magazine and Insurance Monitor 1986;147:22-3.

20 Inter-Departmental Committee on the Rehabilitation of Persons Injured by Accident. Report. London: HMSO, 1938. (Delevigne Committee.)

21 Social Insurance and Allied Services. London: HMSO, 1942. (Beveridge report.)

Accepted 5 February 1990 